\title{
Remote monitoring of patients with cardiac failure
}

\section{Kenneth Dickstein}

\author{
Address: University of Bergen, Stavanger University Hospital, Armauer Hansensvei 20, 4011 Stavanger, Norway \\ Email: kenneth.dickstein@med.uib.no \\ Fl000 Medicine Reports 2009, I:27 (doi: 10.3410/MI-27)
}

The electronic version of this article is the complete one and can be found at: http://www.FI000.com/Reports/Medicine/content/I/27

\begin{abstract}
The area of remote monitoring in cardiac failure is developing rapidly. However, the term is used widely and inconsistently, resulting in difficulty interpreting the literature. Here we assess the recent research into this area and the potential implications for clinical practice.
\end{abstract}

\section{Introduction and context}

Remote monitoring can be summarized as the continuous collection of patient information and the capability to review this information without the patient present. It may refer to data collected through patient contact, as in telemonitoring, or to data collected through telemetry of a device.

Remote monitoring of patients with chronic disease is an emerging area of health care behaviour. Consistent with contemporary health care policy it aims to provide care to the patient in their home and empower them for selfcare. The term remote monitoring is used widely to refer to a variety of models: structured telephone support, remote monitoring of physiological parameters or implantable devices capable of remote patient monitoring and management. Whilst there are distinct differences in these models, they all use information communication technology to monitor the patients' clinical status without face-to-face contact. They focus upon the delivery of care with the patient and health professional separated by distance and emphasise care of the patient in their home. The primary objectives of remote monitoring are to reduce morbidity and detect signs and symptoms of deterioration that might lead to an unnecessary hospitalisation.

\section{Recent advances}

Reflecting the interest in these new models of disease management, McAlister and colleagues [1] updated their earlier systematic review of chronic disease management for patients with heart failure. Grouping telephone and telemonitoring studies together, they demonstrated that these remote monitoring techniques lead to a reduction in heart failure hospitalisations, but had no impact on all-cause hospitalisation rate or mortality. More recently Clark et al. [2] reviewed 14 studies involving 4,264 patients in a meta-analysis of remote monitoring, with studies grouped into those that evaluated telemonitoring or those that evaluated telephone support. They confirmed similar results across the models of remote monitoring: a $20 \%$ reduction in mortality, a $21 \%$ reduction in heart failure admission and no difference in all-cause hospital admission when remote monitoring was compared with usual care. They concluded that these newer models of care offered patient advantage particularly where patients had difficulty accessing specialised care. However, these models of remote monitoring vary considerably in the parameters they monitor and in the involvement of both the patient and health professional, and therefore require further analysis if we are to understand their effective components.

Models of remote monitoring were initially developed using the patients' home phone line. Structured phone support enables the patient to report their self-assessment of symptoms and receive verbal advice and education, usually on a monthly basis [3]. More complex models enable the transfer of physiological data by the patient inputting their data through a telephone touchpad [4]. Increasingly, remote monitoring involves the home installation of simple to use electronic equipment 
such as weighing scales, blood pressure, and heart rate and rhythm monitors to record vital signs linked to the normal home phone-line. The patient uses the monitoring on a daily basis. The clinical data is encrypted and transmitted for professional review at a remote central station [5,6]. As wireless technology develops, data transfer is becoming possible without the need for a direct phone connection.

More complex remote monitoring is now possible through implantable devices that measure intra-thoracic impedance or haemodynamic parameters using sensors incorporated into the device. These devices are able to provide early warning of impending clinical deterioration. They can be added to implantable pacing devices, cardiac resynchronisation therapies (CRTs) or implantable cardioverter defibrillators (ICDs), and set to sound an alarm when a preset threshold is exceeded. Interrogation of the device then reveals clinical parameters suggestive of fluid overload and early management can be instituted. However, these devices remain the subject of robust study and are currently being evaluated in randomised clinical trials. In fact, the 2008 European Society of Cardiology guidelines for the diagnosis and treatment of acute and chronic heart failure [7] provide remote monitoring with a IIb recommendation and level of evidence $\mathrm{C}$, indicating that the usefulness or efficacy of remote monitoring is less well established by evidence and opinion, and that the evidence for remote monitoring practices is the consensus of opinion of the experts and/or small studies, not clinical trials.

\section{Implications for clinical practice}

Health care has developed around a direct encounter between the patient and the professional that involves verbal and non-verbal communication and the exchange of information. Remote monitoring therefore alters traditional models of health care delivery and requires organisational change within the health care system for its full potential to be achieved. Nurses usually play a central role in successful remote monitoring initiatives. Remote monitoring practices vary in important components, such as the amount and type of clinical information transmitted and the patient's involvement in self-monitoring. To fully understand their effectiveness, evaluation should address the process alongside the outcome. Greater clarity over the use of the term would also be valuable when assessing the effectiveness of remote monitoring.
Wider evaluation of these new and complex models of care delivery is required that goes beyond the current reporting of clinical effectiveness. Before such socially complex interventions are routinely adopted we would be wise to evaluate their effect on morbidity, the health care organisation involved and upon patient-centred outcomes.

\section{Abbreviations}

CRT, cardiac resynchronisation therapy; ICD, implantable cardioverter defibrillator.

\section{Competing interests}

The author declares that he has no competing interests.

\section{References}

I. McAlister FA, Stewart S, Ferrua S, McMurray J]: Multidisciplinary strategies for the management of heart failure patients at high risk for admission: a systematic review of randomized trials. J Am Coll Cardiol 2004, 44:810-9.

2. Clark RA, Inglis SC, McAlister FA, Cleland JG, Stewart S: Telemonitoring or structured telephone support programmes for patients with chronic heart failure: systematic review and meta-analysis. BMJ 2007, 334:942.

3. Riegal B, Carlson B, Kopp Z, LePetri B, Glaser D, Unger A: Effect of a standardized nurse case-management telephone intervention on resource use in patients with chronic heart failure. Arch Intern Med 2002, 162:705-12.

4. Capomolla S, Pinna G, La Rovere MT, Maestri R, Ceresa M, Ferrari M, Febo O, Caporotondi A, Guazzotti G, Lenta F, Baldin S, Mortara A Cobelli F: Heart failure case disease management program: a pilot study of home telemonitoring versus usual care. Eur Heart J Supplements 2004, 6 (Suppl F):F9I-8.

5. Cleland JG, Louis AA, Rigby AS, Janssens U, Balk AH, TEN-HMS Investigators: Noninvasive home telemonitoring for patients with heart failure at high risk of recurrent admission and death: the Trans-European Network-Home-Care Management System (TEN-HMS) study. J Am Coll Cardiol 2005, 45: 1654-64.

6. Goldberg LR, Piette JD, Walsh MN, Frank TA, Jaski BE, Smith AL, Rodriguez R, Mancini DM, Hopton LA, Orav EJ, Loh E, WHARF Investigators: Randomized trial of a daily electronic home monitoring system in patients with advanced heart failure: the Weight Monitoring in Heart Failure (WHARF) trial. Am Heart J 2003, I46:705-12.

7. Dickstein K, Cohen-Solal A, Filippatos G, McMurray JJ, Ponikowski P, Poole-Wilson PA, Strömberg A, van Veldhuisen DJ, Atar D, Hoes AW, Keren A, Mebazaa A, Nieminen M, Priori SG, Swedberg K, Vahanian A, Camm J, De Caterina R, Dean V, Dickstein K, Filippatos G, Funck-Brentano C, Hellemans I, Kristensen SD, McGregor K, Sechtem U, Silber S, Tendera M, Widimsky P, Zamorano JL et al.: ESC guidelines for the diagnosis and treatment of acute and chronic heart failure 2008: the Task Force for the diagnosis and treatment of acute and chronic heart failure $\mathbf{2 0 0 8}$ of the European Society of Cardiology. Developed in collaboration with the Heart Failure Association of the ESC (HFA) and endorsed by the European Society of Intensive Care Medicine (ESICM). Eur J Heart Fail 2008, 10:933-89. 